\title{
Measuring the degree of block interdependence between agricultural and non-agricultural sectors in Turkey
}

\section{Serdar Sayan \& Nazmi Demir}

To cite this article: Serdar Sayan \& Nazmi Demir (1998) Measuring the degree of block interdependence between agricultural and non-agricultural sectors in Turkey, Applied Economics Letters, 5:5, 329-332, DOI: 10.1080/758524412

To link to this article: http://dx.doi.org/10.1080/758524412

曲 Published online: 02 Nov 2006.

Submit your article to this journal $\widetilde{ }$

Џ Article views: 29

Q View related articles $\asymp$

4 Citing articles: 2 View citing articles 


\title{
Measuring the degree of block interdependence between agricultural and non-agricultural sectors in Turkey
}

\author{
SERDAR SAYAN and NAZMI DEMIR
}

Department of Economics, Bilkent University, 06533 Bilkent, Ankara, Turkey

Received 22 May 1997

Based on the similarity of productive activities carried out by sectors, national inputoutput (IO) matrices may be divided into sub-matrices each representing a broader group of sectors called blocks. The strength of linkages among sectors that belong to different blocks would then show the degree of block interdependence. The measurement of this degree is useful in many areas including structural change analysis, evaluation of various support policy alternatives or for deciding whether a general or a partial equilibrium framework should be used to investigate the effects of an exogenous shock to a particular sector or a block. This paper introduces a technique that can be used to gauge the degree of block interdependence based on simulation results from demand and supply-side IO models. The application of the technique is illustrated for the case of interdependence between agricultural and non-agricultural blocks in Turkey which recently signed a Customs Union Agreement with the EU. The results indicate that, although Turkey's Agreement covers trade relations in non-agricultural sectors alone, the agricultural sectors must face indirect effects the magnitude of which depend, to a great extent, on the degree of interdependence between blocks considered here.

\section{INTRODUCTION}

Each production sector in an economy is linked to others through the inputs purchased from and outputs delivered to them. The measurement of the strength of these linkages has always been of great interest to economists because of their role in transmitting the effects of various shocks across the economy. This interest explains why almost all countries compile data on intersectoral flows to construct their IO coefficient matrices periodically (Jensen, 1994). A related problem is the measurement of the degree of interdependence between blocks, i.e., broader groups of activities each containing sectors that are interlinked.

This paper introduces an IO-based technique that can be used to gauge the degree of block interdependence. The technique is potentially useful in many areas and links up well with the existing literature on analysis of IO multipliers (Jensen, 1994), identification of key sectors (Chen, 1996), and sources of structural change (Korres, 1996). The use of the technique is illustrated here in reference to the linkages between the agricultural complex (primary agriculture and agricultural processing sectors) and the non-agricultural economy in Turkey. Turkey recently signed a Customs Union Agreement with the EU covering non-agricultural trade alone. The results reported below have been obtained primarily to see whether an investigation of the effects of the Customs Union on Turkish economy may justifiably overlook Turkish agriculture on account of its exclusion from the Agreement. But they are also useful to evaluate the potential effects of agricultural support policy changes on non-agricultural economy. In the light of the post-Uruguay Round tendency in the world to switch from price-distorting subsidies towards decoupled income support to agriculture (Sayan, 1996; Tangermann, 1996), the latter has, in fact, become a question of interest to other countries as well. The degree of interdependence between agricultural and non-agricultural blocks has thus a greater policy relevance for many countries now than before. ${ }^{1}$ The next section of the paper describes the

\footnotetext{
'The conventional IO model briefly described in the next section is a special general equilibrium model characterized by certain restrictions on production, technologies, final demands, and supply schedules for primary production factors (e.g., Hertel, 1990; McGregor et al., 1995). As such, it ignores the changes in relative prices and their resource allocation effects resulting from policy changes. But since a switch to decoupled payments would suppress (or at least minimize) the relative price effects, it is expected to increase the relevance and the predictive power of IO models.
} 
mechanics of the technique. Section III reports results and presents conclusions.

\section{BLOCK INTERDEPENDENCE IN THE IO FRAMEWORK}

The earliest systematic attempt to measure sectoral interdependence was the demand-side IO model developed by Leontief (1936). For the case of $n$ sectors indexed over $i, j \in(1,2, \ldots, k, \ldots, n)$, the material balance equations of the model are

$$
A X+F=X
$$

where $\mathbf{A}$ is an $n \times n$ matrix of IO coefficients, $a_{i, j},{ }^{2} \mathbf{X}$, and $\mathbf{F}$ are $n$-vectors of sectoral outputs and final demands, respectively. Given $\mathbf{F}$ the $\mathbf{X}$ vector solving the system would be

$$
X=(I-A)^{-1} F
$$

where $\mathbf{I}$ is $n \times n$ identity matrix and $\left.(I-A)^{-1}\right)$ is the so-called Leontief inverse.

Since $a_{i, j}$ 's are fixed, Equation 2 shows how sectoral gross domestic outputs (GDOs) would change in response to an exogenous shock affecting $F_{j}$, the final demand for the output of sector $j$. While $a_{i, j}$ 's themselves are indicators of sectoral interdependence within this framework, ${ }^{3}$ it is often the case that exogenous policy changes target or affect a block as a whole rather than an individual sector, or some structural transformation takes place affecting a certain block differently than others.

For such cases, a measure of block interdependence is obtained by partitioning $\mathbf{A}$ into blocks and counterfactually setting the $a_{i, j}$ coefficients capturing the linkages among sectors in different blocks equal to zero. A comparison of the actual (i.e., observed) GDOs and TBLs to those resulting from the counterfactual assumption of a lack of IO linkages across different blocks would show the strength of block interdependence. That is, when the deviations between actual and counterfactual values of GDOs and TBLs turn out to be sufficiently small (large), one can conclude that the block interdependence is weak (strong). ${ }^{4}$ When agricultural and nonagricultural blocks are to be considered, partitioning of $\mathbf{A}$ would be through:

$$
A^{n \times n}=\left[\begin{array}{c|c}
A_{A A}^{k \times k} & A_{A N}^{k \times(n-k)} \\
\hline A_{N A}^{(n-k) \times k} & A_{N N}^{(n-k) \times(n-k)}
\end{array}\right]
$$

Here, $A_{A A}$ is the $k \times k$ matrix of IO coefficients representing flows within the agricultural complex (block). Likewise, the $(n-k) \times(n-k)$ matrix $A_{N N}$ shows the IO coefficients for flows within the non-agricultural block. $A_{N A}$ and $A_{A N}$ are rectangular matrices of size $(n-k) \times k$ and $k \times(n-k)$, respectively, and represent the delivery of inputs from nonagro to agro sectors, and agro inputs received by non-agro sectors. Then, $(I-A)$ is given as:

$$
(I-A)^{n \times n}=\left[\begin{array}{c|c}
D_{A A}^{k \times k} & D_{A N}^{k \times(n-k)} \\
\hline D_{N A}^{(n-k) \times k} & D_{N N}^{(n-k) \times(n-k)}
\end{array}\right]
$$

where the diagonal elements of matrices $D_{A A}$ and $D_{N N}$ are of the form $\left(1-a_{i, j}\right)$, with $-a_{i, j}$ 's elsewhere. The Leontief inverse of this partitioned matrix is

$$
(I-A)^{-1}=\left[\begin{array}{c|c}
\left(D_{A A}-D_{A N} D_{N N}^{-1} D_{N A}\right)^{-1} & -D_{A A}^{-1} D_{A N} B \\
\hline-B D_{N A} D_{A A}^{-1} & B
\end{array}\right]
$$

where $B=\left(D_{N N}-D_{N A} D_{A A}^{-1} D_{A N}\right)^{-1}$.

The counterfactual assumption that changes in the final demands for non-agro (agro) sectors have no impact on agro (non-agro) sectors can be simulated by setting all $a_{i, j}$ 's in $D_{A N}$ $\left(D_{N A}\right)$ equal to zero so that $D_{A N}=\mathbf{O}\left(D_{N A}=\mathbf{O}\right.$, i.e., the null matrix (Carter, 1965). For $D_{A N}=\mathbf{O}$, (5) becomes:

$$
(I-A)^{-1}=\left[\begin{array}{c|c}
D_{A A}^{-1} & O \\
\hline-D_{N N}^{-1} D_{N A} D_{A A}^{-1} & D_{N N}^{-1}
\end{array}\right]
$$

The resulting changes in sectoral GDOs can be found by multiplying the difference between matrices in Equations 5 and 6 by the given $\mathbf{F}$ vector. For agro sectors, for example, the impact on the sectoral GDOs can be found through:

\footnotetext{
${ }^{2}$ Letting $X_{i, j}$ represent the value of purchases of input $i$ by sector $j$, and $X_{j}$ the value of the latter's sectoral output, $a_{i, j}=X_{i, j} / X_{j}$.

${ }^{3}$ Stronger linkages between $j$ and other sectors (higher values of $a_{i, j}$ ) imply that an exogenous shock affecting $F_{j}$. will generate larger effects on outputs of sectors indexed over $i$. A more comprehensive measure of the sectoral interdependence of sector $j$ is given by its total backward linkages (TBLs) that are obtained by finding the sum of the elements in the $j$ th column of $(I-A)^{-1}$. The resulting value shows the change in total intermediate input requirements resulting from a unitary expansion of $F_{j}$ and can be interpreted as the output multiplier for this sector.

${ }^{4}$ The idea was first introduced by Carter (1965) who took the US IO matrix for 1947 and recalculated sectoral outputs assuming a complete lack of IO linkages between agricultural and non-agricultural sectors. Having observed that the deviations between resulting values of sectoral outputs and their actual levels were negligible, Carter concluded that the results supported the independence of agricultural complex from the rest of the economy. Carter's analysis, however, was partial in the sense that he only considered a lack of input demands by non-agricultural sectors for the outputs of agricultural sectors.
} 


$$
\begin{array}{r}
\mathbf{e}_{A}=\left\{\left(D_{A A}-D_{A N} D_{N N}^{-1} D_{N A}\right)^{-1}-D_{A A}^{-1}\right\} \cdot F_{A} \\
\text { and } \epsilon_{A}^{\prime}=e_{A}^{\prime} \cdot \hat{X}_{A}^{-1}
\end{array}
$$

where $\mathbf{e}_{A}$ is the vector of absolute errors in agro GDOs, $\boldsymbol{\epsilon}_{A}^{\prime}$ is the vector of relative errors, and $\hat{X}_{A}^{-1}$ is a diagonalized square matrix of agro GDOs. ${ }^{5}$ For $D_{N A}=\mathbf{O}$, the Leontief inverse to be used for measurement of errors in the GDOs would be

$$
(I-A)^{-1}=\left[\begin{array}{c|c}
D_{A A}^{-1} & -D_{A A}^{-1} D_{A N} D_{N N}^{-1} \\
\hline O & D_{N N}^{-1}
\end{array}\right]
$$

This analysis measuring the degree of demand-side interdependence between blocks is partial and must be repeated using the supply-side variant of the traditional IO model developed by Ghosh (1958). Letting $\ddot{\mathbf{A}}$ and VA represent the $n \times n$ matrix of coefficients $\ddot{a}_{i, j}=X_{i, j} / X_{i}$, and the row vector of sectoral value-addeds respectively, the supply-side equivalent of Equation 1 would be

$$
X^{\prime} \ddot{A}+V A=X^{\prime}
$$

where prime $\left({ }^{\prime}\right)$ is the transpose operator. Then, for any given VA, the solution of the system would be

$$
X^{\prime}=V A(I-\ddot{A})^{-1}
$$

where $(I-\ddot{A})^{-1}$ is the supply-side version of the Leontief inverse. Within this framework, $\ddot{a}_{i, j}$ 's show the supply generation capacity of sector $i$ following an increase in the availability of labour or any other productive factor for its production. By increasing the output of sector $i$, this will relax the input constraint facing other sectors that use $i$ as an intermediate input. $^{6}$

The supply-side IO models will generate the same solution as in Equation 2 for the base year (Bon and Bing, 1993).
There, however, is no assurance that the GDOs projected by the demand-side model in response to a change in $\mathbf{F}$ would be matched by those projected by the supply-side model in response to a change in VA. Counter-factual experiment results for both cases must therefore be considered before deciding how strongly the agricultural block is linked to the rest of the economy. Given

$$
\ddot{A}^{n \times n}=\left[\begin{array}{c|c}
\ddot{A}_{A A}^{k \times k} & \ddot{A}_{A N}^{k \times(n-k)} \\
\hline \ddot{A}_{N A}^{(n-k) \times k} & \ddot{A}_{N N}^{(n-k) \times(n-k)}
\end{array}\right]
$$

and $\mathbf{S}$ the partitioned version of $(I-\ddot{A})$, two-way sensitivity measures may be obtained as before, under the assumptions that $S_{A N}=\mathbf{O}$ and $S_{N A}=\mathbf{O}$, i.e., changes in primary factor employment by agro sectors (non-agro sectors) have no effect on non-agro (agro) sectors.

\section{THE RESULTS AND CONCLUSIONS}

The results below were obtained from a 32-sector (Appendix), aggregated version of the 64-sector IO transaction matrix of Turkey for 1990 published by Turkish State Institute of Statistics. ${ }^{7}$ The Table 1 shows mean percentages of relative errors in the GDOs and backward/forward linkages resulting from counterfactual assumptions considered.

The GDO results indicate that when agro input purchases of non-agricultural sectors are assumed zero, agro (non-agro) sectors face sizable losses in GDOs under the demand-side (supply-side) model. When non-agro input purchases of

\begin{tabular}{|c|c|c|c|c|c|c|}
\hline \multirow[b]{2}{*}{ Assumption } & \multicolumn{3}{|c|}{ Relative errors in total linkages (mean $\%$ ) } & \multicolumn{3}{|c|}{ Relative errors in gross domestic outputs (mean \%) } \\
\hline & Whole economy & Agro sectors & Nonagro sectors & Whole economy & Agro sectors & Nonagro sectors \\
\hline & \multicolumn{3}{|c|}{ Backward linkages } & \multicolumn{3}{|c|}{ Demand-side model } \\
\hline$D_{A N}=\mathbf{O}$ & 3.49 & 0.73 & 7.53 & 14.68 & 23.57 & 1.69 \\
\hline \multirow[t]{2}{*}{$D_{N A}=\mathbf{O}$} & 12.33 & 19.58 & 1.90 & 7.38 & 1.08 & 16.60 \\
\hline & \multicolumn{3}{|c|}{ Forward linkages } & \multicolumn{3}{|c|}{ Supply-side model } \\
\hline$S_{N A}=\mathbf{O}$ & 5.24 & 1.04 & 11.36 & 16.32 & 25.82 & 2.45 \\
\hline$S_{A N}=\mathbf{O}$ & 10.66 & 17.11 & 1.23 & 3.53 & 0.75 & 7.59 \\
\hline
\end{tabular}
agricultural sectors are assumed zero, on the other hand, the sectors facing sizable GDO losses under the demand-side (supply-side) model would be non-agro (agro) sectors. The downward bias in agro GDOs under $D_{A N}=\mathbf{0}$, is very high

Table 1. Mean percentages of relative errors in total linkages and GDOs

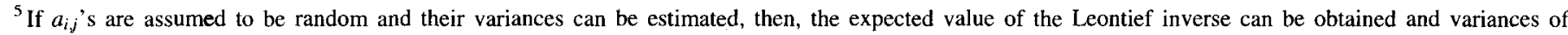
multipliers can be found as in Jansen (1994). This would allow for probabilistic tests on the assumptions of block independence and would be an area for improved results.

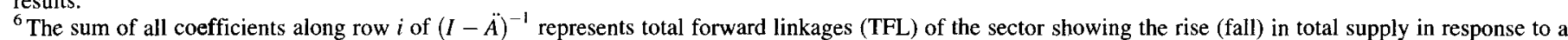
unit increase (decrease) in primary factor use by sector $i$.

${ }^{7}$ The IO coefficients used here are based on total flows covering both domestically produced and imported products. While there are alternative views concerning this treatment (Miller and Blair, 1985), a test comparing multipliers under total versus domestic flows for 1990 did not yield significant differences.
} 
approaching $24 \%$. Under $S_{N A}=\mathbf{O}$, the bias is $25.82 \%$ on the average for agro sectors, clearly illustrating the high level of interdependence of agro sectors as users of inputs supplied by non-agro sectors (e.g., chemicals, petroleum products, machinery). Likewise, the average loss in non-agro GDOs standing at $7.59 \%$ under $S_{A N}=\mathbf{O}$ indicate that agro sectors are important suppliers of inputs for others as well.

As for the impacts on multipliers, TBLs are found to be pretty sensitive to both assumptions (particularly to $D_{A N}=\mathbf{O}$ for non-agro, and to $D_{N A}=\mathbf{O}$ for agro sectors). Relative errors in multipliers averaging $3.49 \%(12.33 \%)$ for the whole economy under $D_{A N}=\mathbf{O}\left(D_{N A}=\mathbf{O}\right)$ signal a strong interdependence between agro and non-agro blocks. Following a change in $F_{A}$, total input requirements of agro sectors from others are significantly distorted when relevant linkages are ignored. The supply-side model shows even stronger and more diffused linkages requiring that more attention be given to the supply multiplying ability of the sectors when additional resources are to be allocated. Concerning the overall pattern of errors, $D_{A N}=\mathbf{O}$ and $S_{N A}=\mathbf{O}$ yield the same ups and downs while the magnitudes hint stronger forward linkages than backward linkages for all but especially agro sectors.

In summary, both total linkages and sectoral GDOs are found to be grossly underestimated when agro and non-agro sectors are assumed not linked, implying a considerable reduction in the predictive power of the Leontief inverse. Despite variation in sectoral results not reported here, the sensitivity analyses conducted provide evidence generally supportive of the argument that the agro complex in Turkey can not be taken in isolation from other sectors. This, in turn, implies that the Customs Union with the EU will have considerable impacts not only on non-agricultural sectors but also on Turkish agriculture although agricultural trade is not covered by the Agreement.

\section{REFERENCES}

Bon, R. and Bing, X. (1993) Comparative stability analysis of demand-side and supply-side input-output models in the UK, Applied Economics, 25, 75-79.

Carter, H.O. (1965) Measurement of the Degree of Interdependence between Agricultural Complex and Non-agriculture, Unpublished Report, Harvard University, Cambridge.

Chen B. (1996) Picking winners and industrialization in Taiwan, The Journal of International Trade and Economic Development, 5 , 137-59.

Ghosh, A. (1958) Input-output approach to an allocative system, Economica, 25, 58-64.

Hertel, T.W. (1990) General equilibrium analysis of US agriculture: what does it contribute? Journal of Agricultural Economics Research, 42, 3-8.

Jansen, P.S.M., Kop (1994) Analysis of multipliers in stochastic input-output models, Regional Science and Urban Economics, $24,55-74$.

Korres, G.M. (1996) Sources of structural change: an input-output decomposition analysis for Greece, Applied Economics Letters, 3, 707-10.

Leontief, W. (1936) Quantitative input-output relations in the economic system of the United States, Review of Economics and Statistics, 18, 105-25.

McGregor, P.G., Swales, J.K. and Yin, Y.P. (1995) Input-output analysis, labour scarcity and relative price endogeneity: aggregate demand disturbances in a 'flex-price' Leontief system, Economic Systems Research, 7, 189-208.

Miller, R.E and Blair, P.D. (1985) Input-Output Analysis: Foundations and Extensions, Prentice Hall, Englewood Cliffs.

Sayan, S. (1996) Budget deficits and agricultural support spending: general equilibrium effects under alternative support schemes, Yapi Kredi Economic Review, 7, 27-46.

Tangermann, S. (1996) Implementation of the Uruguay Round Agreement on agriculture: issues and prospects, Journal of Agricultural Economics, 47, 315-37.

\section{APPENDIX: SECTOR COVERAGE OF THE INPUT-OUTPUT MODEL}

Present study
Agro sectors
1 Crops
2 Livestock
3 Forestry
4 Fishery
5 Slaughtering
6 Fruit and vegetable processing
7 Vegetable and livestock oil
8 Cereal processing
9 Sugar
10 Other food processing
11 Alcoholic drinks
12 Non-alcoholic drinks
13 Tobacco processing
14 Ginning
15 Textiles
16 Leather and furs
17 Wood products
18 Furniture
19 Paper products

Non-agro sectors

20 Mining

21 Shoes and apparel

22 Printing etc.

23 Fertilizers

24 Chemicals

25 Petroleum products

26 Rubber and plastics

27 Glass and cement

28 Steel and metal products

29 Machinery and vehicles

30 Construction and other manufacturing

31 Utilities

32 Services
Original SIS table

1 Crops

2 Livestock

3 Forestry

4 Fishery

11 Slaughtering

12 Fruit and vegetable processing

13 Vegetable and livestock oil

14 Cereal processing

15 Sugar

16 Other food processing

17 Alcoholic drinks

18 Non-alcoholic drinks

19 Tobacco processing

20 Ginning

21 Textiles

23 Leather and furs

25 Wood products

26 Furniture

27 Paper products

5-10 Various mining sectors

22-24 Shoes and apparel

28 Printing etc.

29 Fertilizers

30-31 Medicines and chemicals

32-33 All petroleum products

34-35 Rubber and plastic products

36-38 Glass and cement

$39-41$ Steel and metal products

42-48 All machinery and vehicles

$49,52,53$ Construction and other manufacturing

50-51 Electricity, gas and water

54-64 All services 